\title{
Public Attention Helps Stocks Survive During Circuit-Breaker Period in China
}

\author{
Sili Wei \\ School of Management and Economics, The Chinese University of Hong Kong, Shenzhen, \\ Shenzhen 518172, China \\ a114020283@link.cuhk.edu.cn
}

\begin{abstract}
The relationship between public attention and stock has been researching for years in the field of behavioral finance. This paper studied the effect of public attention on excess return under extreme market condition of the 4-day circuit-breaker period of China in 2016. After constructing the sample from Wind dataset, we found that there exists a significant positive relationship between excess return of a stock and incremental proportion of discussion on a particular stock. We conjecture that this effect on stock returns is due to the change in public attention. This characteristic is helpful when investors want to hedge or generate excess return under extreme market condition.
\end{abstract}

Keywords: public attention, circuit-breaker period, excess return.

\section{Introduction}

The aspect of the characteristics we want to research is public attention. In foreign market, the effect of public attention has been proved in many research. Thomas J. Chemmanur and An Yan researched the effect of advertising on stock returns [1]. Brad M and Terrance Odean researched that what sort of stocks that individual investors will buy when they have thousands of choices [2]. Zhi Da, Joseph Engelberg \& Pengjie Gao showed that search volume index can strongly predict positive revenue surprises [3]. Another paper of Azi Ben-Rephael, Zhi Da, and Ryan D. Israelsen proposed a measure of abnormal institutional investor attention using news search on Bloomberg terminal and found it highly correlated with institutional trading measure [4]. But in China, relative research is scarce. Besides, for all the paper mentioned above, their research was completed under a normal market situation. For the extreme market condition in China, it remains mysterious and complex. Combining the research done by them, we got the inspiration and want to analyze that whether public attention in China will play an important role in stock characteristic and affect stock return under extreme market condition. Nonetheless it was tough for us to find an appropriate sample since what is the definition of extreme market condition. Fortunately, in 2016, the circuit-breaker mechanism was run and triggered, which is enough to let us treat the market as an extreme one and provided us with an excellent sample, since "the circuit-breaker mechanism, is a financial regulatory instrument that is in place to prevent stock market crashes". [5]. It originated from U.S after the 1987 market crash known as Black Monday. Currently, many countries financial markets like U.S, France, Japan and Singapore adopt a similar mechanism in form of price limit or trading halt. The Chinese version circuit breaker mechanism was raised from Sep.2015 and run from Jan 1st 2016. The initial goal of imposing such a mechanism in China is to protect retail investors whose trading volume occupy $80 \%$ of total volume in China. Unfortunately, on the contrast, this mechanism was ceased just after 4-day official run (Jan 1st 2016- Jan 3rd 2016 are not trading days). It's a short-lived mechanism, but it caused a huge loss to the market. Shanghai Stock Exchange Composite Index and Shenzhen Component Index on average decreased by $13.37 \%$ just in four days. For most individual stocks, the loss was even bigger. Astonishingly, a small part of stocks survived from the extreme market situation and even beat the market. So, this paper is not intended to discuss the pros and cons of this mechanism. It focuses on the characteristic that those winner stocks have during the market crash. Even though the circuit breaker mechanism has been halted, the frequency of market crash in China is relatively high comparing to other main financial market thorough out the world. So, the value of this research is that if the characteristics can be discovered, investors can try adjust their portfolios based on characteristics during next market crash to assist them hedging by holding these stocks. For market 
regulators, it's also helpful since they can establish appropriate institute based on characteristic to reduce the market loss.

\section{Data and methodology}

\subsection{Data range \& source}

Based on the background and introduction of this paper, the crucial data collected is mainly from the circuit breaker period, which lasted for approximately 4 days, from Jan 4th 2016 to Jan. 7th 2016. The dataset used is Wind Finance terminal, which is the 'Chinese Bloomberg'. For equity research, it contains all public and disclosed information of total listed 3327 firms (ended in 2016) in the Ashare market. Users can select variables from its variable contents, extract corresponding numerical data and form an Excel sheet conveniently. To guarantee the accuracy and reliability of results, all data we used are from this terminal.

\subsection{Model and Dependent variable selection}

The goal of this paper is to test whether the public attention will help a stock generate excess return during the circuit breaker period (extreme market situation) in China. So, it is a cross-sectional regression, referring some ideas from the classical cross-sectional regression model raised by Fama and Macbeth [6]. We built the regression model as following

$\mathrm{ER}_{\mathrm{i}}=\beta_{0}+\beta_{1} * \gamma_{\mathrm{i}}+\varphi_{\mathrm{j}} * \vec{X}+\varepsilon_{\mathrm{i}}$

where

$\gamma_{\mathrm{i}}=$ the core variable we want to test in model

$\vec{X}=$ a vector of other control variables

$\beta_{1}=$ coefficient of variable $\gamma_{i}$

$\varphi_{\mathrm{j}}=$ coefficient of corresponding variable in variable vector $\vec{X}$

$\varepsilon_{\mathrm{i}}=$ regression error term

The dependent variable in the above model is Excess Return $(E R)$. The ER is defined as following, but we made some modifications comparing with the original Fama and Macbeth model

$\mathrm{ER}_{\mathrm{i}}=\mathrm{CR}_{\mathrm{i}}-\beta_{\mathrm{i}} \mathrm{CR}$ m

where

$\mathrm{ER}_{\mathrm{i}}=$ the excess return of stock $\mathrm{i}$

$\mathrm{CR}_{\mathrm{i}}=$ the 4-day cumulative return of stock $\mathrm{i}$

$\beta_{\mathrm{i}}=$ the TTM (ended at Dec.2015) beta of stock i corresponding to market return

$\mathrm{CR}_{\mathrm{m}}=$ the 4-day cumulative return of market index

$\mathrm{CR}_{\mathrm{i}}$ is calculated as

$\mathrm{CR}_{\mathrm{i}}\left(1+\mathrm{r}_{\mathrm{Jan} 4^{\mathrm{th}}}\right) *\left(1+\mathrm{r}_{\text {Jan } 5^{\text {th }}}\right) *\left(1+\mathrm{r}_{\mathrm{Jan} 6^{\text {th }}}\right) *\left(1+\mathrm{r}_{\mathrm{Jan} 7^{\mathrm{th}}}\right)-1$

where

$\mathrm{r}_{\text {Jan } 4^{\text {th }}}=$ The rate of return of the stock on Jan 4th 2016

$\mathrm{r}_{\text {Jan } 5^{\mathrm{th}}}=$ The rate of return of the stock on Jan 5th 2016

$r_{\text {Jan } 6^{\text {th }}}=$ The rate of return of the stock on Jan 6th 2016

$\mathrm{r}_{\text {Jan }} 7^{\mathrm{th}}=$ The rate of return of the stock on Jan 7th 2016

$\mathrm{CR}_{\mathrm{m}}$ is calculated similarly as $\mathrm{CR}_{\mathrm{i}}$

\subsection{Core variable selection}

Based on model (1), after defining the dependent variable, next step is to plug in the core variable $\gamma_{i}$. In our research, the most concerned thing is whether public attention will have an effect on stock return, so it's the core variable. In model, the proxy of public attention used in model is the incremental proportion of discussion on a particular stock on www.Xueqiu.com in one week (Oneweek) recorded by Wind finance terminal. The inspiration of using this proxy mainly comes from Zhi.Da \& Joseph Engelberg \& pengjie Gao [3]. In their paper, the proxy of they used is search volume index(SVI) on Google, which is reliable and convincing since Google is a mature search engine. For small search engines, their search volume may not be representative for public attention. 
Just for the same reason, the Oneweek variable was used in our model, since Xueqiu.com is the top 1 comprehensive finance website in China with over 1million daily active users (based on the statistic from iresearch data). So, the user's activity on it can represent the public investor in a large degree. The Oneweek variable is defined as

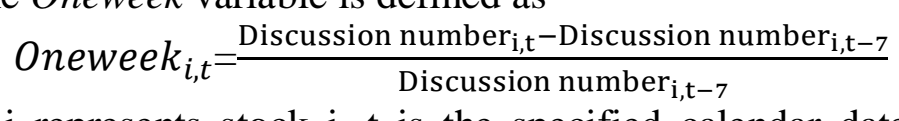

$\mathrm{i}$ represents stock $\mathrm{i}, \mathrm{t}$ is the specified calendar date, in our model, $\mathrm{t}=\mathrm{Jan} 7$ th 2016 . For unit convenience, in regression, we directly use Oneweek\%.

\subsection{Other control variables selection}

In variable vector $\vec{X}$, we included following variables

lnsize $=$ The natural logarithm of a stock's market capitalization

Turnover=The average turnover during the 4-day period

$\mathrm{M} / \mathrm{B}=$ the market to book ratio of stock

According to Zhi Da, Joseph Engelberg \& Pengjie Gao, on average, firms that advertise on national TV are larger firms with higher turnover and growth firms [3]. So, more advertisement may attract public attention and discussion on Internet, which means that the Oneweek variable may not be an independent characteristic of a stock, it was just another proxy for those large, higher turnover and growth firms. Additionally, based on Fama and French, the M/B effect, size effect.

Table 1. Statistic Summary

\begin{tabular}{cccc} 
Variable & Mean & Median & St. Deviation \\
\hline Excess Return(ER) & -0.059 & -0.067 & 0.089 \\
Oneweek\% & 1.033 & 0.530 & 2.035 \\
Insize $($ billion $)$ & 2.44 & 2.278 & 0.823 \\
M/B & 7.562 & 3.932 & 47.12 \\
turnover \% & 1.378 & 1.378 & 1.450
\end{tabular}

(Small-firm-in-January effect), Neglected-firm and liquidity effect can explain most abnormal return (Excess Return) of a stock [7]. Besides, in Zhi Da [3], they used above three control variables in their model as well.

If after adding these variables into our model, Oneweek variable becomes insignificant, which means the Oneweek may not be a good proxy for public attention, it just a proxy for the above three variables. If Oneweek is still significant, at least, we can say conclude it can explain some of excess return of a stock during the circuit breaker period.

\subsection{Sample construction}

The initial sample was all the stocks in both Shanghai and Shenzhen Stock Exchange, but it should be modified to fit the model. Since the dependent variable we used is cumulative excess return of a stock during the period, those ceased trading stocks should be excluded from the sample. So, those stocks with zero trading volume and zero rate of return during that four days are kicked out from the sample. Besides, in order to get the excess return of a stock, we require the beta (corresponding to market index SSECI) of a stock, however, for those stocks whose IPO are less than 1 year (before Jan 4th 2015), their betas are not accurate and convincing. Additionally, in Chinese stock market, these stocks attract large number of speculators who will cause the volatile price change. This will probably result in bias in the final result, so these stocks are also moved out from sample. At last, since the main independent variable tested in our model is the incremental public attention proportion on a particular stock (Oneweek variable), but for some stocks, this number is not recorded by the dataset, to get a balanced cross-sectional data sample, the missed part is excluded as well. After these treatments on sample, 2074 observations left.

\subsection{Summary statistics}

Table 1 contains summary statistic of the sample we constructed. For Excess Return

$(E R)$, the mean is $-5.9 \%$, which means on average all the stocks in the market loss $5.9 \%$ more than market index, so it's necessary and attractive to research those winner stocks in such an extreme market situation, what factor or characteristics they have to help them beat the market? In next section, further explanation will be given. 


\section{Empirical Result}

Table 2. Regression result

\begin{tabular}{ccccc}
\hline \multicolumn{5}{c}{ Dependent Variable: Excess return(ER) } \\
& Oneweek\% & turnover & $M / B$ & lnsize \\
\hline Coefficient & $0.00493 * * *$ & $0.0173 * * *$ & $-9.35 * 10-6$ & $0.0272 * * *$ \\
Standard error & $(0.000991)$ & $(0.00141)$ & $(3.80 * 10-5)$ & $(0.00221)$ \\
\hline Observations & \multicolumn{4}{c}{2074} \\
Adjust R2 & \multicolumn{4}{c}{0.1569} \\
\hline Note: the value with $* * *$ represents that its significant level is less than 0.01
\end{tabular}

\subsection{Core variable.}

Table. 2 shows the result from regression. It proves that our hypothesis is true. The three control variables including turnover, $M / B$, and Insize were added into model, it shows that the coefficient of Oneweek remains significant, they have negligible effect on the variable of interest. For economic meaning of this result, if the weekly number of attention on a stock increased by $1 \%$, it can contribute about 40-50 bps to excess return, which may help the stock survive under the extreme market situation. Barder and Ordean shows that retail investors are net buyers of "attention grabbing" stocks, e.g., stocks in the news, having high abnormal trading volume, or experiencing extreme one-day return [2]. The same logic applied to our result. More number of attention can bring more potential investors for a stock, which will push price up and generate positive excess return. The positive excess motivates more investors to buy the stock. They reciprocally push each other, because Bank and Peter showed that stocks grabbing more attention may enjoy a continuous increase in price due to the attention induced boom [8]. After the increase in stock price, investors might believe the winning position is accomplished by their accurate prediction of the market trend, and would be trapped in self-attribution bias and further establish their position in these stocks. Last but not least, familiarity bias may also play a crucial role. People tend to be more familiar with those attention-grabbing stocks. This familiarity triggers investors to value those stocks more than others. When a shock incurs, this bias exerts influence in two ways: first, individuals might hesitate to give up their current position, they might have positive expectation on those attention-grabbing stocks they are familiar with, and would probably hedge against the shock by purchasing those stocks.

\subsection{Other variables}

For the three control variables, we selected, the result is consistent with what Zhi Da, Joseph Engelberg \& Pengjie Gao got [3]. We would expect that the $B / M$ variable is significant, because growth stocks with low $B / M$ (i.e. high $M / B$ ) can grab more attentions comparing with those value stocks with high $B / M$. A possible explanation for the insignificance is that finance indicators like $B / M$ ratio are used in long term investment, $B / M$ effect exists only in relative long period. But for this extreme short 4-day period, it's not surprising that $B / M$ ratio becomes ineffective.

As for the rest two control variables, their result is reasonable. Higher turnover means more investors traded this stock during 4-day period. This provides liquidity to the market, which will not cause great panic to retail investors and let them sell their stock without any consideration resulting in price collapse. Stocks with big market capitalization can provide more liquidity comparing to small cap stocks, which can prevent price collapse in some degree, so the coefficient of Insize is positive.

\section{Conclusion}

Motivated by other researches in public attention effect on stock market, we used the incremental proportion of discussion on a particular stock on www.Xueqiu.com in one week (Oneweek) as the proxy for public attention in our model. We found that if the Oneweek increases, the excess return of a stock increases. We also found that the predictive power of Oneweek did not reduce and vanish even after controlling other important variables whose effectiveness have proved. Combining our findings suggests that public attention really has an effect on stock excess return during market crash period in China. This conclusion is also similar to what Chemmanur and Yan found in their paper [1]. They concluded that a greater amount of advertising is associated with a larger stock return in the 
advertising year (short run) but a smaller stock return in the year subsequent (long run) to the advertising year even after controlling for other price indicators. For our result, it's exactly significant in 4-day period (short run) as well. Thus, Oneweek is a crucial characteristic which cannot be ignored by investors in China as well. For investors, if next market crash occurs, they can overweight those stocks with more public attention in their portfolio. For firms who want to survive during a market crash, they should probably increase the public attention of their stock by interacting with investors more frequently and disclose necessary information of their stocks.

Even though we have proved that public attention can have influence, we only used one proxy for it. There possibly exists other better proxy for it like the click number of new of a particular stock. Besides, we only checked the period from Jan 4th 2016 to Jan 7th 2016, whether the result of this research is still powerful or not? Or can we extend this conclusion into a longer period like the total recession period of the stock market? We leave these questions for further research.

\section{References}

[1]. Chemmanur T J. Advertising, Attention, and Stock Returns[J]. Social Science Electronic Publishing, 2009.

[2]. Barber B M, Odean T. All That Glitters: The Effect of Attention and News on the Buying Behavior of Individual and Institutional Investors[J]. Review of Financial Studies, 2008, 21(2):785-818.

[3]. Da, Z., and J, Engelberg, and P.Gao, 2010, In Search of Attention[J]. Journal of Finance, June 4th 2009.

[4]. Ben-Rephael A, Da Z, Israelsen R D. It Depends on Where You Search: Institutional Investor Attention and Under-Reaction to News[J]. Social Science Electronic Publishing, 2016.

[5]. Information on: https://en.wikipedia.org/wiki/Trading_curb

[6]. Fama E F, Macbeth J D. Risk, Return, and Equilibrium: Empirical Tests[J]. Journal of Political Economy, 1973, 81(Volume 81, Number 3):607-636. 636

[7]. Fama E F, French K R. Common risk factors in the returns on stocks and bonds[J]. Journal of Financial Economics, 1993, 33(93):3-56.

[8]. Bank M. Public Attention, Adverse Selection, and the Pricing of Stocks[J]. Ssrn Electronic Journal, 2010. 